\section{Robust cellular reprogramming occurs spontaneously during liver regeneration}

\author{
Kilangsungla Yanger, ${ }^{1,2,6}$ Yiwei Zong,, ,2,6 \\ Lara R. Maggs, ${ }^{1,2}$ Suzanne N. Shapira, ${ }^{1,2}$ \\ Ravi Maddipati, ${ }^{1,2}$ Nicole M. Aiello, ${ }^{1,2}$ \\ Swan N. Thung, ${ }^{3}$ Rebecca G. Wells, ${ }^{1}$ \\ Linda E. Greenbaum, ${ }^{4}$ and Ben Z. Stanger ${ }^{1,2,5,7}$ \\ ${ }^{1}$ Department of Medicine, Gastroenterology Division, \\ ${ }^{2}$ Abramson Family Cancer Research Institute, Perelman School \\ of Medicine, University of Pennsylvania, Philadelphia, \\ Pennsylvania 19104, USA; ${ }^{3}$ Department of Pathology, Mount \\ Sinai School of Medicine, New York, New York 10029, USA; \\ ${ }^{4}$ Department of Cancer Biology, Jefferson University School \\ of Medicine, Philadelphia, Pennsylvania 19107, USA; \\ ${ }^{5}$ Department of Cell and Developmental Biology, Perelman \\ School of Medicine, University of Pennsylvania, Philadelphia, \\ Pennsylvania 19104, USA
}

Cellular reprogramming-the ability to interconvert distinct cell types with defined factors-is transforming the field of regenerative medicine. However, this phenomenon has rarely been observed in vivo without exogenous factors. Here, we report that activation of Notch, a signaling pathway that mediates lineage segregation during liver development, is sufficient to reprogram hepatocytes into biliary epithelial cells (BECs). Moreover, using lineage tracing, we show that hepatocytes undergo widespread hepatocyte-to-BEC reprogramming following injuries that provoke a biliary response, a process requiring Notch. These results provide direct evidence that mammalian regeneration prompts extensive and dramatic changes in cellular identity under injury conditions.

Supplemental material is available for this article.

Received October 8, 2012; revised version accepted February $25,2013$.

In adult tissues, rates of cell birth and death are tightly controlled to maintain tissue mass. During amphibian regeneration, dedifferentiation and/or transdifferentiation are a major source of new cells ( Nacu and Tanaka 2011). In contrast, mammalian regeneration is driven by the replication of existing cells or differentiation from stem cells. Transdifferentiation, or cellular reprogramming, has been observed in mammals following the introduction of defined factors in vivo (Xie et al. 2004; Zhou et al. 2008), but spontaneous interconversion of

[Keywords: liver; regeneration; facultative stem cells; reprogramming] ${ }^{6}$ These authors contributed equally to this work.

${ }^{7}$ Corresponding author.

E-mail bstanger@exchange.upenn.edu

Article published online ahead of print. Article and publication date are online at http://www.genesdev.org/cgi/doi/10.1101/gad.207803.112. differentiated cells seems to occur only in the setting of strong selective pressure (Thorel et al. 2010). "Metaplasia" - a condition in which the replacement of one tissue type with another predisposes to cancer-may involve cellular reprogramming, but the connection between metaplasia at the tissue level and transdifferentiation at the cellular level remains unresolved (Slack 2009).

The mammalian liver is exceptional among regenerative organs in that the mode of injury is thought to dictate the cellular mechanism of recovery. Following partial removal of the liver (partial hepatectomy [PHx]), liver mass is restored by replication and/or growth of existing cells (Miyaoka et al. 2012), whereas following toxinmediated injury, animals and humans exhibit an accumulation of atypical ductal cells (ADCs) within the liver, often referred to as "oval cells" (Farber 1956; Popper et al. 1957). In this study, we sought to determine whether cellular plasticity underlies the regenerative response of the liver.

\section{Results and Discussion}

In newborn mice, immature hepatocytes remain responsive to Notch signals and undergo a fate switch, becoming biliary epithelial cells (BECs) upon ectopic activation of the pathway (Zong et al. 2009). To determine whether adult hepatocytes retain this competence, we simultaneously labeled cells and induced Notch signaling with recombinant adeno-associated virus $2 / 8$ (AAV2/8), a viral serotype that exhibits hepatocyte-specific tropism and rapid clearance (Gao et al. 2006; Zincarelli et al. 2008; Malato et al. 2011). We confirmed this specificity, showing that upon infection of $\operatorname{Ros}^{Y F P}$ reporter mice with either of two Cre-bearing viruses (AAV8-TBG-Cre or AAV8-CMV-Cre) (see the Materials and Methods), all labeled cells expressed $\mathrm{HNF} 4 \alpha$, a hepatocyte marker (3948 $\mathrm{YFP}^{+}$cells examined, $N=4$ mice), while none expressed CK19, a BEC marker $\left(1351\right.$ CK19 ${ }^{+}$cells examined, $N=6$ mice) (Supplemental Fig. 1A,C,E). We further confirmed specificity by fluorescence-activated cell sorting (FACS), showing a complete absence of overlap in staining with the BEC marker EpCAM (Okabe et al. 2009) and YFP (Supplemental Fig. 7A,B). Furthermore, labeling was highly efficient, with $>99 \%$ of hepatocytes labeled (Supplemental Fig. 1A-F).

Next, we bred Rosa ${ }^{Y F P}$ mice to Rosa ${ }^{N I C D}$ mice, which harbor a Cre-inducible constitutively active form of Notch1 (Fig. 1A; Murtaugh et al. 2003; Zong et al. 2009). As predicted, infection of bigenic Rosa $a^{N I C D / Y F P}$ mice with AAV8-TBG-Cre resulted in the activation of Notch signaling (as assessed by Hes1 expression) in $>95 \%$ of hepatocytes (Fig. 1B). Within 1 wk of virus injection, we observed frequent costaining for the hepatocyte marker HNF4 $\alpha$ and the BEC markers Sox $9178.7 \% \pm$ $8.9 \%, N=3$ ), osteopontin (OPN; $51.9 \% \pm 17.5 \%, N=3$ ) (Fig. 1C), and HNF1 $\beta$ (Supplemental Fig. 2B). Importantly, the virus itself did not induce expression of BEC markers (Supplemental Fig. 2A). Such biphenotypic cells were seen throughout the lobule, with the exception of "zone $3^{\prime \prime}$ hepatocytes located adjacent to central veins, which did not stain with BEC markers despite evidence of Notch activation (Supplemental Fig. 2C). Examination of the YFP lineage label confirmed that these cells were of hepatocyte origin (Fig. 1D), and limiting dilution experiments showed 
Yanger et al.

A

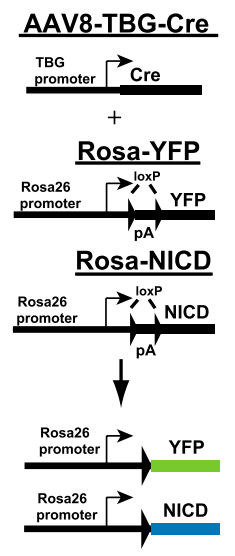

D

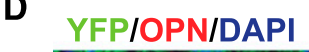

B
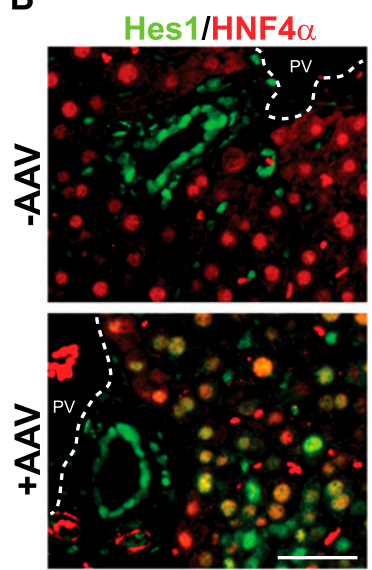

C
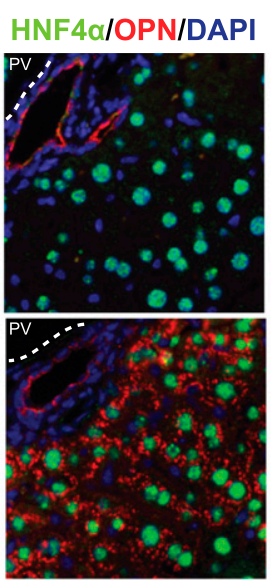

$\mathbf{F}$

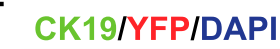

CK19/YFPIDAPI

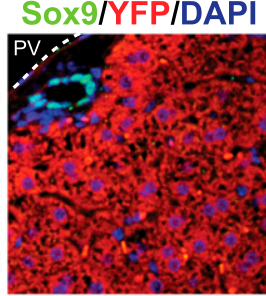

E Par6/HNF4a/DAPI
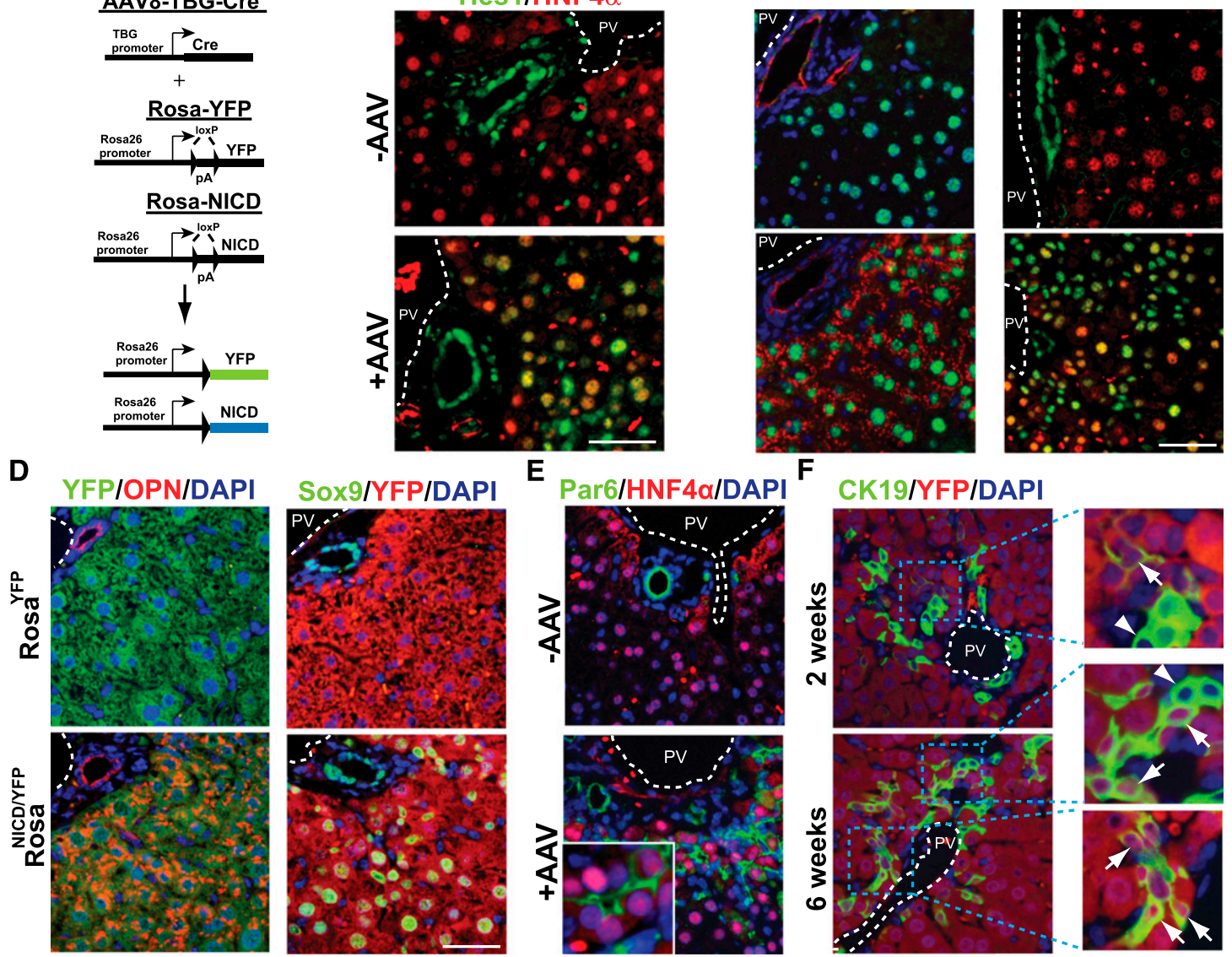

Figure 1. Notch signaling triggers hepatocyte-to-BEC reprogramming. $(A)$ Schematic of simultaneous lineage labeling (YFP) and activation of Notch intracellular domain (NICD) expression by AAV administration. (B) Hes1 is expressed in most HNF4 $\alpha^{+}$hepatocytes 1 wk after Notch activation. $(C)$ Notch activation in hepatocytes for 1 wk leads to an "intermediate" phenotype characterized by coexpression of BEC markers (OPN and Sox9) and HNF4 $\alpha$. Portal veins (PV) are denoted by white dotted lines. (D) YFP lineage-labeled hepatocytes express OPN and Sox9 upon Notch activation. $(E)$ HNF4 $\alpha^{+}$hepatocytes express a BEC apical marker, Par6, after 2 wk of Notch activation. $(F)$ Notch signaling reprograms hepatocytes into terminally differentiated BECs. Weak CK19 staining is observed in YFP $^{+}$cells 2 wk after infection, while robust CK19 expression in $\mathrm{YFP}^{+}$cells appears $6 \mathrm{wk}$ after infection. (Insets) Reprogrammed $\mathrm{CK}_{1} 9^{+} \mathrm{YFP}^{+}$cells are denoted with arrows, and "unreprogrammed" CK19+YFP" cells are denoted with arrowheads. These images are representative of at least five independent experiments. Bar, $25 \mu \mathrm{m}$.

that the Notch effect was cell-autonomous (Supplemental Fig. 2D). Many of the hepatocyte-derived cells assumed a biliary morphology and exhibited alterations in cell polarity, forming small duct-like structures that stained with the apical markers Par6, PKC $\zeta$, and acetylated tubulin (Fig. 1E; Supplemental Fig. 2E). Lineagelabeled cells with weak CK19 staining (CK19 $\left.{ }^{\text {lo }}\right)$ were detected 2 wk after AAV8-TBG-Cre injection (Fig. 1F, 2 wk) and increased over time (Supplemental Fig. 4A), while $\mathrm{YFP}^{+}$cells with strong CK19 staining (CK19 $\left.{ }^{\text {hi }}\right)$ were detected $6 \mathrm{wk}$ after injection (Fig. 1F, $6 \mathrm{wk}$ ) and comprised $23 \%$ of all CK19 cells examined (128 out of 561 CK19 cells; $N=3$ mice). Hence, ectopic activation of Notch signaling reprograms a subset of hepatocytes into BEClike cells.

Toxic liver injuries result in an ADC or "oval cell" response. ADCs have a biliary phenotype, but their arrangement into an intricate anastomosing configuration that extends into the hepatic lobule gives them a histological appearance that is distinct from normal bile ducts (Desmet 1985). We noted that the reprogrammed BEC-like cells resulting from Notch activation resembled ADCs, prompting us to hypothesize that some ADCs might be hepatocyte-derived. To test this possibility, we administered AAV8-TBG-Cre to Rosa ${ }^{\text {YFP }}$ mice and, following a washout period, treated animals with the hepatotoxin DDC (3,5-diethoxycarbonyl-1,4-dihydrocollidine). DDC treatment was associated with a robust ADC response during which a substantial fraction of hepatocytes and BECs underwent turnover (Supplemental Fig. 3). Within 1-2 wk of DDC exposure, cells that costained with biliary and hepatocyte markers were readily detectable. These biphenotypic "intermediate" cells were most abundant in periportal regions, and many were binucleated (for example, $41 \%$ of $\mathrm{A}^{+} \mathrm{HNF} 4 \alpha^{+}$ cells had two nuclei) (Fig. 2A). In addition, staining for the YFP lineage marker demonstrated that all biphenotypic and CK $19^{\text {lo }}$ cells were hepatocyte-derived, with weak CK19 expression detected after 2-3 wk of DDC treatment (Supplemental Fig. 4B,C). After 6 wk of DDC 
A
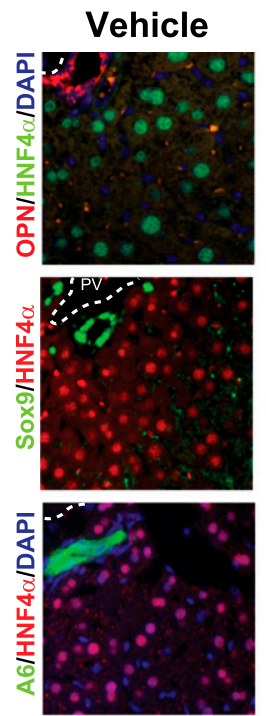

C

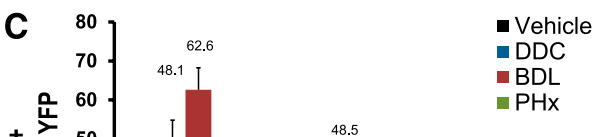

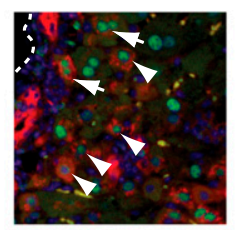
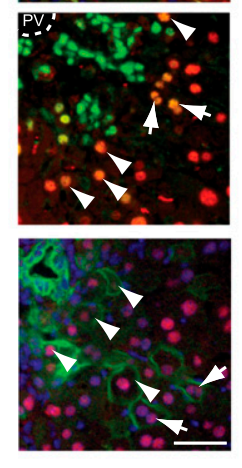

Vehicle

BDL

$\mathrm{PHx}$
B Vehicle

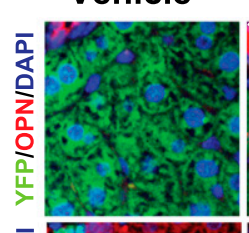

DDC
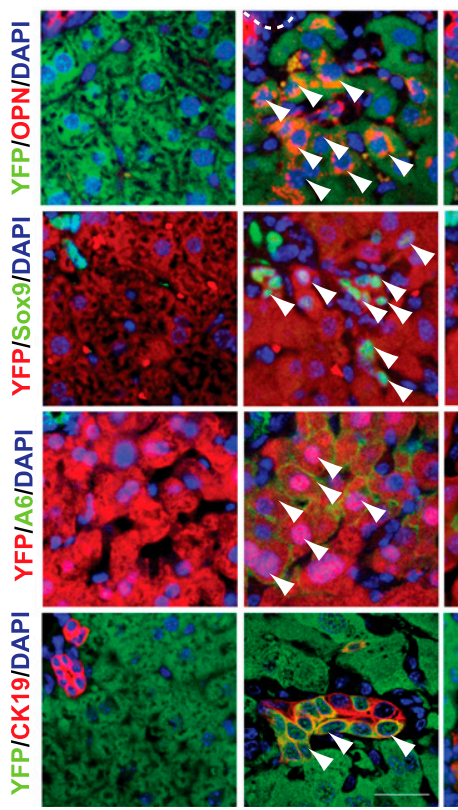

BDL
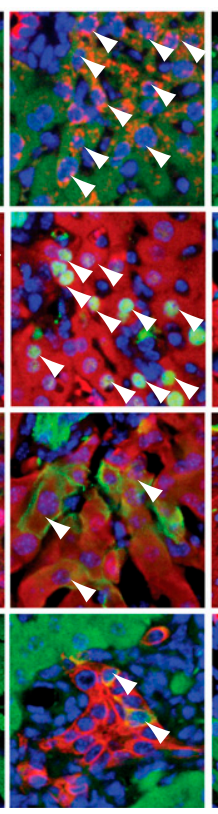

PHx

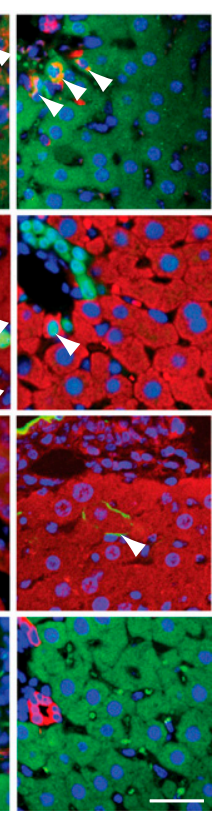

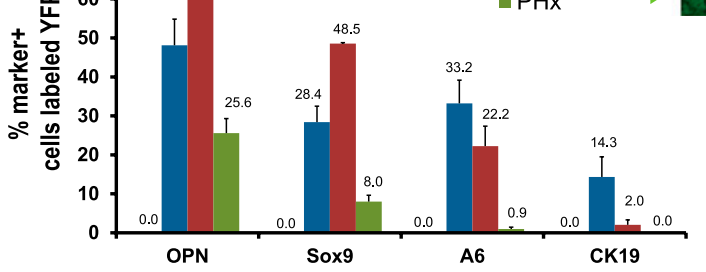

Figure 2. Direct evidence for hepatocyte-to-ADC reprogramming in vivo. (A) Mice treated with DDC for 1 wk exhibit costaining with a hepatocyte marker (HNF4 $\alpha$ ) and one of three biliary markers (OPN, Sox9, or A6). Double-positive cells have a hepatocyte morphology (arrowheads), and many are binucleated (arrows). The images are representative of multiple experiments. $(B)$ Costaining of the biliary markers OPN, A6, Sox9, and CK19 with the YFP lineage label was observed following DDC treatment (6 wk), BDL (2 wk), or PHx ( $2 \mathrm{wk}$ ); costained cells are denoted with arrowheads. Note that many of the costained cells are smaller than neighboring hepatocytes. $(C)$ Biliary markers are induced in a stepwise fashion following injury. The percentage of marker ${ }^{+}$cells (i.e., cells that stained positive for OPN, Sox9, A6, or CK19) that coexpress the YFP lineage label is shown. Both CK19hi and CK19lo cells were included in the analysis. Double-positive cells were not detected in vehicletreated livers. Each bar represents the mean $( \pm \mathrm{SE})$ of at least three mice; a minimum of 950 marker ${ }^{+}$cells were examined for each data point. Bars, $25 \mu \mathrm{m}$.

treatment, a time point when ADCs were most plentiful, we observed that many $\mathrm{YFP}^{+}$cells had assumed a biliary morphology and costained with OPN, A6, Sox9, or CK19 (Fig. 2B). At this time point, YFP $^{+}$cells with strong CK19 staining (CK19 ${ }^{\text {hi }}$ ) comprised $4.4 \%$ of the total $\mathrm{CK} 19^{+}$ population (Supplemental Fig. 4D). The frequency of costaining with YFP depended on the biliary marker used, ranging from $48.1 \%$ of $\mathrm{OPN}^{+}$cells to $14.3 \%$ of $\mathrm{CK} 19^{+}$cells (Fig. 2C).

To determine whether this phenotypic conversion is a generalized feature of liver damage, we performed other types of injury in animals with lineage-labeled hepatocytes. As with DDC treatment, we observed changes in the morphology of $\mathrm{YFP}^{+}$cells and costaining of YFP and biliary markers in the setting of ductular reactions caused by other stimuli-including bile duct ligation (BDL) and other injuries (Fig. 2B,C; Supplemental Fig. 5, respectively)although the frequency of costaining varied with the type of injury. Following $\mathrm{PHx}$, in contrast, $\mathrm{YFP}^{+}$cells that had adopted a biliary morphology or stained weakly for CK19 were never observed $(N=5)$, although staining for OPN, Sox9, and (rarely) A6 was seen in some hepatocytes (Fig. $2 \mathrm{~B}, \mathrm{C})$. These results suggest that toxin-based injuries and $\mathrm{BDL}$ (insults that provoke an $\mathrm{ADC}$ response) are associated with stepwise hepatocyte-to-BEC reprogramming, while PHx (an injury that predominantly involves cell replication and hypertrophy) does not lead to cellular conversion.

The appearance of biphenotypic cells in a variety of rodent injury models prompted us to analyze human liver specimens for evidence of hepatocyte-to-BEC reprogramming in the setting of injury. As described for other liver diseases with biliary involvement (Limaye et al. 2008), we found abundant cells that coexpressed the hepatocyte markers HNF $4 \alpha$ and HepPar1 and the BEC marker Sox9 in liver sections from patients with several types of liver disease, whereas such cells were never observed in control human liver specimens (Supplemental Fig. 6). These results suggest that the cellular plasticity observed in the rodent injury models may also operate during human liver injury.

To determine the extent to which hepatocyte-derived BECs acquire features of normal BECs, we performed a more detailed morphological and molecular analysis of DDC-treated livers. Within 3 wk of DDC treatment, YFP cells underwent dramatic morphological changes, including 
the acquisition of a distinctive apical-basal polarity (detected by staining for PKC $\zeta$ and Par6), a reduction in cell size, and coalescence into neo-lumens (Fig. 3A). $\mathrm{YFP}^{+}$cells in DDC-treated livers also exhibited the development of primary cilia, a biliary-specific organelle marked by acetylated tubulin (Ac-tub) (Fig. 3B). Finally, we obtained molecular evidence that the hepatocyte-derived BECs closely resemble normal BECs. Hepatocyte-derived $\mathrm{YFP}^{+}$BECs were captured using FACS and assessed by quantitative PCR (qPCR) for multiple BEC markers. These reprogrammed cells exhibited transcript levels for these genes comparable with those of bona fide BECs (Supplemental Fig. 7C-E), indicating that they had acquired many of the transcriptional hallmarks of normal biliary cells. Notably, hepatocyte-derived BECs and $\mathrm{YFP}^{+}$hepatocytes (including those at early stages of biliary reprogramming) did not express the hepatoblast marker $\alpha$-fetoprotein (AFP), suggesting that the conversion process does not go through a dedifferentiation step (Supplemental Fig. 7F). Collectively, these results indicate that following injury in vivo, hepatocytes can turn into cells that closely resemble normal BECs at the morphological, structural, and molecular levels.

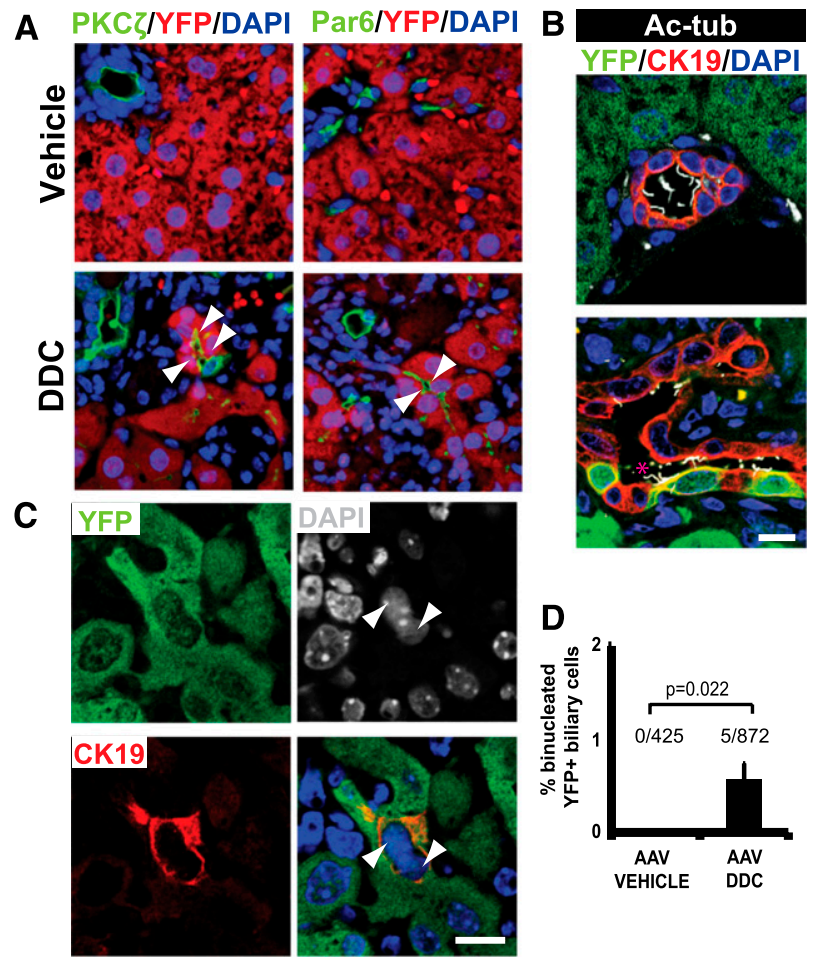

Figure 3. Hepatocytes undergo morphological changes during reprogramming. (A) $\mathrm{YFP}^{+}$hepatocytes change their morphology after DDC injury, organizing into duct-like structures with neo-lumens marked by the apical polarity markers PKC $\zeta$ and Par6 (arrowheads). (B) Reprogrammed cells have cilia, marked by acetylated tubulin (6 wk, Ac-tub; pink asterisk). (C) Reprogramming leads to binucleated ADCs. Sections of liver from AAV8-TBG-Cre-labeled animals given DDC were costained with DAPI (gray/blue), YFP (green), and CK19 (red) and examined by confocal microscopy. Binucleated $\mathrm{ADCs}$ were present in the $\mathrm{YFP}^{+}$population. $(D)$ Quantification of binucleated BECs in labeled mice given normal chow (AAV vehicle) or DDC (AAV DDC); the number of cells counted $(N=3$ mice in each group) is shown. Bars, $10 \mu \mathrm{m}$.
Next, we sought independent evidence for a hepatocyte origin of ADCs using ploidy characterization. More than $30 \%$ of normal murine hepatocytes are binucleated, whereas BECs are mononucleated (Gupta 2000). We reasoned, therefore, that some hepatocyte-derived ADCs might be binucleated. Consistent with this notion, binucleated ADCs were found in DDC-treated livers, whereas none were detected in control livers $10.6 \%$ vs. $0.0 \%$ ) (Fig. 3C,D). All binucleated ADCs expressed the YFP lineage maker, suggesting that polyploidy was restricted to hepatocyte-derived BECs (Fig. 3C).

Finally, we examined the molecular mechanism underlying the hepatocyte-to-BEC conversion. As Notch overexpression itself induced hepatocyte reprogramming (Fig. 1), we used mice with a liver-specific deletion of $R B P-J \kappa$ - an essential component of the canonical Notch pathway-to determine whether Notch signaling is also required for reprogramming under injury conditions. We and others have shown that deletion of $R B P-J \kappa$ in the embryonic liver using the $A F P^{C r e}$ strain results in a bile duct paucity due to Notch's role in biliary specification (Zong et al. 2009; Sparks et al. 2010). We found that treatment of $A F P{ }^{C r e}$; $R B P-J \kappa^{L / L}$ mice (referred to as "AFP-RBP" mice) with DDC resulted in a marked reduction in the ADC response compared with controls (Supplemental Fig. 8A,B), a result that provides genetic evidence that Notch signaling is required for the generation of ADCs. However, since $A F P^{C r e}$ mediates deletion in embryonic hepatoblasts, AFP-RBP mice lack $R B P-J_{\kappa}$ in both hepatocytes and BECs. Hence, the defective ADC response could be the result of $R B P-J \kappa$ loss in either, or both, of these cellular compartments.

To determine whether Notch is involved in hepatocyte-to-ADC reprogramming, we administered AAV8TBG-Cre to $\mathrm{RBP}^{\mathrm{L} / \Delta}$ mice harboring one "floxed" allele and one null allele of $R B P-J_{\kappa}\left({ }^{\prime \prime} \mathrm{L} / \Delta^{\prime \prime}\right)$ and to control $\mathrm{RBP}{ }^{\mathrm{L} / \mathrm{WT}}$ mice harboring one wild-type allele of $R B P-J \kappa\left({ }^{\prime \prime} \mathrm{L} / \mathrm{WT}\right.$ ") (Fig. 4A). We used an AAV8-TBG-GFP virus lacking Cre as an additional control (Supplemental Fig. 8C,D). Following a week-long washout period, animals in both groups were fed DDC for $3 \mathrm{wk}$. As expected, control animals exhibited abundant biphenotypic cells. In contrast, RBP knockout mice exhibited dramatic decreases in biphenotypic cells (Supplemental Fig. 8C,D) and hepatocyte-derived Sox $9^{+}$ and $\mathrm{OPN}^{+}$cells (Fig. 4B,C), including an $\sim 20$-fold decrease in the number of reprogrammed $\mathrm{CK} 19^{+}$cells compared with wild-type animals (data not shown). This result indicates that $R B P-J \kappa$ is required for biliary reprogramming.

Most examples of mammalian reprogramming, such as the landmark discovery that fibroblasts can be converted to pluripotent cells (Takahashi and Yamanaka 2006), use the ectopic expression or activity of defined factors in vitro. In 2004, Wagers and Weissman (2004) established a set of stringent criteria by which to assess bona fide reprogramming events in vivo, a list that includes demonstrating proper integration of the transdifferentiated cells within the tissues. Our studies regarding the conversion of hepatocytes to BECs fulfill these criteria. We showed that following the expression of a single transcription factor (NICD) or multiple types of hepatic injury, hepatocytes gradually lose their identity and acquire a biliary phenotype in vivo. As part of this Notch-dependent process, cells transit through an intermediate state, characterized by the coexpression of hepatocyte- and BECspecific transcription factors, and adopt morphological 
A

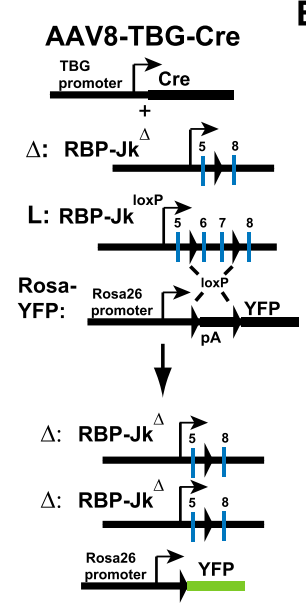

B

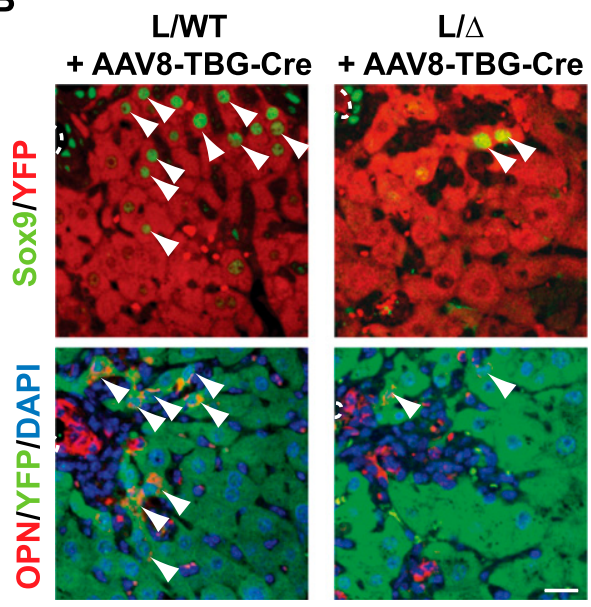

C
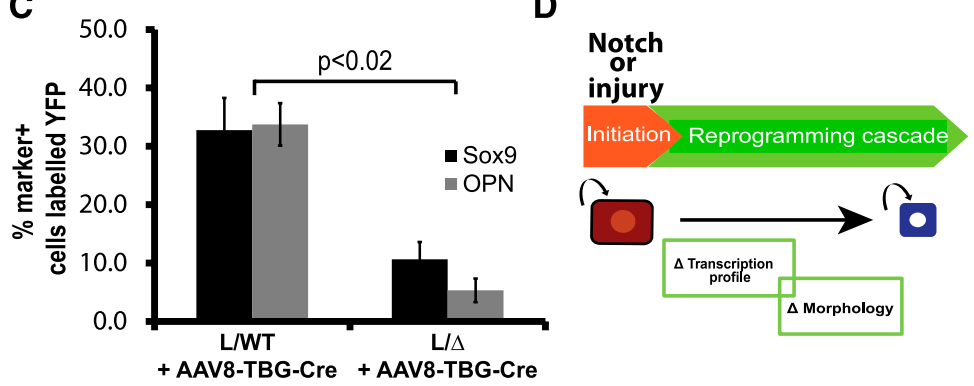

Figure 4. Hepatocyte reprogramming requires Notch signaling. (A) Schematic of simultaneous deletion of RBPJк and lineage tracing of hepatocytes. $(B)$ Mice with hepatocyte-specific deletion of RBP-Jк have a significant reduction in the number of "intermediate" cells. Concomitant hepatocyte labeling and RBP-Jк deletion results in a reduction in the percentage of hepatocyte-derived Sox ${ }^{+}$or $\mathrm{OPN}^{+}$ cells after DDC treatment $(3 \mathrm{wk}) .(C)$ Quantification of $B$, depicting the percentage of $\mathrm{Sox}^{+}$or $\mathrm{OPN}^{+}$cells that carry the YFP lineage marker $(N=4$ mice each group). (D) Model for hepatocyte-to-ADC reprogramming, a Notchdependent cascade of transcriptional changes and alterations in cellular morphology. Bars, $25 \mu \mathrm{m}$.

features of BECs (Fig. 4D). Given the role that Notch plays as a major fate determinant during normal biliary differentiation, we postulate that adult hepatocyte-to-BEC reprogramming is a recapitulation of this developmental process. Moreover, the prevalence of the phenomenon suggests that cellular reprogramming is a generalized component of the liver's normal response to injury, particularly those injuries-like DDC treatment and BDL (but not PHx) - that evoke a biliary response. The abundance of biphenotypic cells in human liver disease (Limaye et al. 2008; this study) suggests that biliary reprogramming may be common in humans as well.

Our results are in accordance with older studies that used $\left[{ }^{3} \mathrm{H}\right]$-thymidine incorporation, immunostaining, and electron microscopy to examine the origins of ADCs in vivo (Factor et al. 1994). In those experiments, newly emergent ADCs had ultrastructural features of hepatocytes and were commonly found in close apposition to hepatocytes as they expanded into the lobule. In light of our lineage tracing results, we propose that these observations reflect the retention, rather than the acquisition, of hepatocyte features during reprogramming, an idea that first emerged $>50$ years ago when ADCs were initially described as "ductular hepatocytes" (Leduc 1959).
Previous work has hinted at the possibility that hepatocytes can transdifferentiate into BECs, including experiments involving chimeric livers with BDL and methylene diamiline injury (Michalopoulos et al. 2005), transplantation of hepatocytes into the spleen (Fukuda et al. 2004; Watanabe et al. 2008), and the development of cholangiocarcinomas following oncogene misexpression in hepatocytes (Fan et al. 2012; Sekiya and Suzuki 2012). In contrast, Malato et al. (2011) reached an opposite conclusion regarding hepatocyte plasticity. Our studies suggest that BEC reprogramming occurs as a cascade, similar to the stepwise reprogramming described for induced pluripotent cells (Plath and Lowry 2011). The progressive nature of the process may provide an explanation for the failure of Malato et al. (2011) to observe biliary reprogramming following injury, as their study relied on the single BEC marker CK19. Our study also demonstrates that cellular reprogramming occurs in vivo in the absence of the strong selective pressures introduced by transplantation or carcinogenesis. It remains unknown whether cellular proliferation is required for this process. Some forms of reprogramming, such as induced pluripotency (Takahashi and Yamanaka 2006), require cell proliferation, while other forms, such as acinar-to- $\beta$-cell reprogramming, do not (Zhou et al. 2008). In our system, injuries that provoke biliary reprogramming are associated with a high degree of cellular turnover and occur over a long period of time (2-4 wk); hence, more refined methods will be needed to probe this cellular conversion process.

In summary, we showed that hepatocytes initiate an in vivo differentiation program following injury that results in their conversion into biliary cells. This process occurs in a stepwise fashion that involves the induction of biliary markers, a decrease in cell size, formation of a polarized epithelial layer, and the formation of new and potentially functional organelles. These results thus provide a dramatic example of how cellular reprogramming - a process that has been mainly associated with lower organisms - can contribute to mammalian regeneration. Our findings also suggest that hepatocyte pliability may be able to serve as a cellular source for the production of BECs in diseases that are characterized by loss or dysfunction of these cells, such as cholestasis or Alagille syndrome.

\section{Materials and methods}

\section{Animals}

Mice were maintained in a pathogen-free environment. $A F P^{C r e}, R_{O S a}{ }^{Y F P}$, $R B P-J \kappa$, and Rosa ${ }^{N I C D}$ strains have previously been described (Kellendonk et al. 2000; Srinivas et al. 2001; Han et al. 2002; Murtaugh et al. 2003). Descriptions of the mouse injury models can be found in the Supplemental Material.

\section{Viral infections}

Replication-incompetent AAVs were obtained from the Penn Vector Core. AAV8-TBG-Cre carries Cre recombinase under the regulatory control of the hepatocyte-specific thyroid-binding globulin (TBG) promoter, while 
AAV8-CMV-Cre carries Cre recombinase under the regulatory control of the ubiquitous CMV promoter. In vivo cell labeling with AAV8-TBG-Cre and AAV8-CMV-Cre was achieved by giving mice of the appropriate genetic background $2.5 \times 10^{11}$ viral particles (regular dose) diluted in sterile $1 \times$ PBS. For activating Notch signaling in differentiated hepatocytes, AAV-TBG-Cre was administered to mice via retro-orbital injection at a dose of $1 \times 10^{11}$ genome copies per animal (or $1 \times 10^{10}$ genome copies per animal diluted in PBS for low-dose experiments).

\section{Acknowledgments}

We thank K. Kaestner and T. Honjo for providing $\mathrm{AFP}^{\mathrm{Cre}}$ and RBP-Jк mice, and V. Factor and D. Melton for providing A6 and CK19 antibodies. We thank J. Hui for help with the BDL protocol; A. Panikkar, S. Small, A. Rhim, Z. Shen, M. Maijenburg, and C. Yang for technical assistance; the University of Pennsylvania Flow Cytometry and Cell Sorting Resource Laboratory; the University of Pennsylvania CDB Microscopy core; and the Penn Digestive Disease Center and Abramson Family Cancer Research Institute (AFCRI) histology cores for sample processing. We are indebted to F. Camargo and K. Zaret for insightful discussions on the manuscript. This study was supported by Public Health Service grants DK083355 and DK090306 and the Pew Charitable Trusts.

\section{References}

Desmet VJ. 1985. Intrahepatic bile ducts under the lens. J Hepatol 1: 545559.

Factor V, Radaeva S, Thorgeirsson S. 1994. Origin and fate of oval cells in dipin-induced hepatocarcinogenesis in the mouse. Am I Pathol 145: 409-422.

Fan B, Malato Y, Calvisi DF, Naqvi S, Razumilava N, Ribback S, Gores GJ, Dombrowski F, Evert M, Chen X, et al. 2012. Cholangiocarcinomas can originate from hepatocytes in mice. J Clin Invest 122: 29112915.

Farber E. 1956. Similarities in the sequence of early histological changes induced in the liver of the rat by ethionine, 2-acetylamino-fluorene, and 3'-methyl-4-dimethylaminoazobenzene. Cancer Res 16: 142-148.

Fukuda K, Sugihara A, Nakasho K, Tsujimura T, Yamada N, Okaya A, Sakagami M, Terada N. 2004. The origin of biliary ductular cells that appear in the spleen after transplantation of hepatocytes. Cell Transplant 13: 27-33.

Gao G, Lu Y, Calcedo R, Grant R, Bell P, Wang L, Figueredo J, Lock M, Wilson J. 2006. Biology of AAV serotype vectors in liver-directed gene transfer to nonhuman primates. Mol Ther 13: 77-87.

Gupta S. 2000. Hepatic polyploidy and liver growth control. Semin Cancer Biol 10: 161-171.

Han H, Tanigaki K, Yamamoto N, Kuroda K, Yoshimoto M, Nakahata T, Ikuta K, Honjo T. 2002. Inducible gene knockout of transcription factor recombination signal binding protein-J reveals its essential role in $\mathrm{T}$ versus B lineage decision. Int Immunol 14: 637-645.

Kellendonk C, Opherk C, Anlag K, Schutz G, Tronche F. 2000. Hepatocyte-specific expression of Cre recombinase. Genesis 26: 151-153.

Leduc EH. 1959. Cell modulation in liver pathology. I Histochem Cytochem 7: 253-255.

Limaye PB, Alarcon G, Walls AL, Nalesnik MA, Michalopoulos GK, Demetris AJ, Ochoa ER. 2008. Expression of specific hepatocyte and cholangiocyte transcription factors in human liver disease and embryonic development. Lab Invest 88: 865-872.

Malato Y, Naqvi S, Schürmann N, Ng R, Wang B, Zape J, Kay M, Grimm D, Willenbring H. 2011. Fate tracing of mature hepatocytes in mouse liver homeostasis and regeneration. J Clin Invest 121: 1850-1860.

Michalopoulos GK, Barua L, Bowen WC. 2005. Transdifferentiation of rat hepatocytes into biliary cells after bile duct ligation and toxic biliary injury. Hepatology 41: 535-544.

Miyaoka Y, Ebato K, Kato H, Arakawa S, Shimizu S, Miyajima A. 2012. Hypertrophy and unconventional cell division of hepatocytes underlie liver regeneration. Curr Biol 22: 1166-1175.

Murtaugh LC, Stanger BZ, Kwan KM, Melton DA. 2003. Notch signaling controls multiple steps of pancreatic differentiation. Proc Natl Acad Sci 100: 14920-14925.

Nacu E, Tanaka EM. 2011. Limb regeneration: A new development? Annu Rev Cell Dev Biol 27: 409-440.
Okabe M, Tsukahara Y, Tanaka M, Suzuki K, Saito S, Kamiya Y, Tsujimura T, Nakamura K, Miyajima A. 2009. Potential hepatic stem cells reside in $\mathrm{EpCAM}^{+}$cells of normal and injured mouse liver. Development 136: 1951-1960.

Plath K, Lowry WE. 2011. Progress in understanding reprogramming to the induced pluripotent state. Nat Rev Genet 12: 253-265.

Popper H, Kent G, Stein R. 1957. Ductular cell reaction in the liver in hepatic injury. J Mt Sinai Hosp N Y 24: 551-556.

Sekiya S, Suzuki A. 2012. Intrahepatic cholangiocarcinoma can arise from Notch-mediated conversion of hepatocytes. I Clin Invest 122: 3914-3918.

Slack JM. 2009. Metaplasia and somatic cell reprogramming. I Pathol 217: 161-168.

Sparks EE, Huppert KA, Brown MA, Washington MK, Huppert SS. 2010. Notch signaling regulates formation of the three-dimensional architecture of intrahepatic bile ducts in mice. Hepatology 51: 1-10.

Srinivas S, Watanabe T, Lin CS, William CM, Tanabe Y, Jessell TM, Costantini F. 2001. Cre reporter strains produced by targeted insertion of EYFP and ECFP into the ROSA26 locus. BMC Dev Biol 1: 4.

Takahashi K, Yamanaka S. 2006. Induction of pluripotent stem cells from mouse embryonic and adult fibroblast cultures by defined factors. Cell 126: 663-676.

Thorel F, Népote V, Avril I, Kohno K, Desgraz R, Chera S, Herrera P. 2010. Conversion of adult pancreatic $\alpha$-cells to $\beta$-cells after extreme $\beta$-cell loss. Nature 464: 1149-1154.

Wagers A, Weissman I. 2004. Plasticity of adult stem cells. Cell 116: 639648.

Watanabe H, Hata $M$, Terada N, Ueda H, Yamada N, Yamanegi K, Ohyama H, Kakihana M, Okamura H, Nakasho K. 2008. Transdifferentiation into biliary ductular cells of hepatocytes transplanted into the spleen. Pathology 40: 272-276.

Xie H, Ye M, Feng R, Graf T. 2004. Stepwise reprogramming of B cells into macrophages. Cell 117: 663-676.

Zhou Q, Brown J, Kanarek A, Rajagopal J, Melton DA. 2008. In vivo reprogramming of adult pancreatic exocrine cells to $\beta$-cells. Nature 455: 627-632.

Zincarelli C, Soltys S, Rengo G, Rabinowitz JE. 2008. Analysis of AAV serotypes 1-9 mediated gene expression and tropism in mice after systemic injection. Mol Ther 16: 1073-1080.

Zong Y, Panikkar A, Xu J, Antoniou A, Raynaud P, Lemaigre F, Stanger BZ. 2009. Notch signaling controls liver development by regulating biliary differentiation. Development 136: 1727-1739. 


\section{Erratum}

Genes \& Development 27: 719-724 (2013)

Robust cellular reprogramming occurs spontaneously during liver regeneration

Kilangsungla Yanger, Yiwei Zong, Lara R. Maggs, Suzanne N. Shapira, Ravi Maddipati, Nicole M. Aiello, Swan N. Thung, Rebecca G. Wells, Linda E. Greenbaum, and Ben Z. Stanger

For the above-mentioned article, two panels in Figure 1E (illustrating Par6 staining) were inadvertently duplicated in Supplemental Figure 2E (illustrating PKC $\zeta$ staining). This error in Supplemental Figure 2E has been corrected in the Revised Supplemental Fig. 2 online. The authors apologize for this error. 


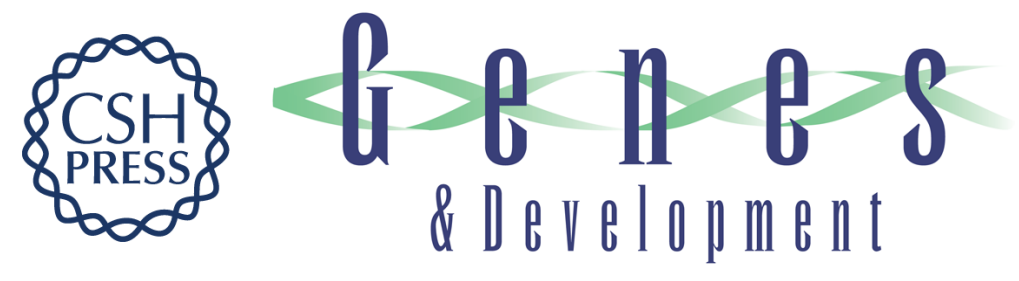

\section{Robust cellular reprogramming occurs spontaneously during liver regeneration}

Kilangsungla Yanger, Yiwei Zong, Lara R. Maggs, et al.

Genes Dev. 2013, 27: originally published online March 21, 2013

Access the most recent version at doi:10.1101/gad.207803.112

\section{Supplemental http://genesdev.cshlp.org/content/suppl/2013/03/20/gad.207803.112.DC1 \\ Material http://genesdev.cshlp.org/content/suppl/2013/06/18/gad.207803.112.DC2}

Related Content Robust cellular reprogramming occurs spontaneously during liver regeneration Kilangsungla Yanger, Yiwei Zong, Lara R. Maggs, et al.

Genes Dev. July, 2013 27: 1537

References This article cites 31 articles, 4 of which can be accessed free at:

http://genesdev.cshlp.org/content/27/7/719.full.htmI\#ref-list-1

Articles cited in:

http://genesdev.cshlp.org/content/27/7/719.full.htmI\#related-urls

\section{License}

Email Alerting Receive free email alerts when new articles cite this article - sign up in the box at the top Service right corner of the article or click here.

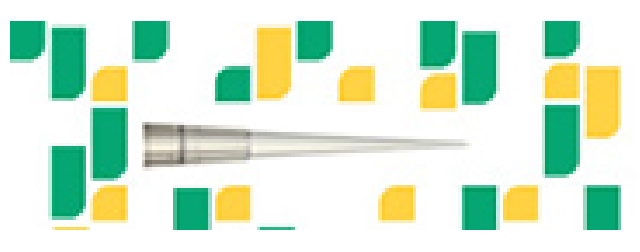

Focused on your science. 